\title{
A utilização de material lúdico acessível em uma escola da zona rural do município de Marabá, Pará, Brasil
}

The use of accessible play material in a public school in the rural municipality of Marabá, Pará, Brazil

\author{
B. B. Pinto; D. R. M. da Costa* \\ Centro de Ciências Sociais e Educação, Universidade do Estado do Pará(UEPA), 68500-000, Marabá/PA, Brasil. \\ *danymont@uepa.br
}

(Recebido em 08 de abril de 2016; aceito em 03 de maio de 2016)

\begin{abstract}
A utilização de materiais lúdicos no ensino em geral está conquistando um amplo espaço de atuação, pois anteriormente eram vistas como brincadeiras, modo de esgotar energia excedente dos alunos ou preenchimento de espaço vago durante as aulas. Com o desenvolvimento de metodologias utilizadas no ensino, os métodos lúdicos são aplicados como modo de fixar conteúdos propiciando aos alunos a interação social, raciocínio lógico e desenvolvendo o processo de ensino-aprendizagem dos mesmos de forma considerável. No ensino de ciências biológicas a utilização do método lúdico possibilita o desenvolvimento das aulas, tornando-as mais dinâmicas e interativas, fugindo da monotonia das aulas tradicionais. O presente trabalho foi realizado em uma escola situada na zona rural do município de Marabá/PA utilizando materiais lúdicos na disciplina de biologia sobre a teoria da evolução de Lamarck e Darwin, os resultados foram positivos sobre o processo de ensino-aprendizagem dos alunos, pois foi o primeiro contato de mais de $72 \%$ dos alunos do $7^{\circ}$ ano "A" com materiais lúdicos em sala de aula.

Palavras-chaves: Teoria da evolução, Materiais lúdicos, Ensino-aprendizagem.
\end{abstract}

The use of playful materials in education in general is conquering an ample space of performance, therefore previously they were seen as tricks, way to deplete exceeding energy of the pupils or fulfilling of vacant space during the lessons. With the development of methodologies used in education, the playful methods are applied as way to set contents propitiating to the pupils the social interaction,logical reasoning and developing the process of teach-learning of the same of considerable form. In the education of biological sciences the use of the playful method makes possible the development of the lessons,returning them more dynamic and interactive, running away from the monotony of the traditional lessons. The present work was accomplished in a situated school in the rural area of the city of Marabá/PA using material playful in the discipline of biology on the theory of the evolution of Lamarck and Darwin, the results was positive on the process of teach-learning of the pupils, therefore year "A" with playful materials in classroom was the first contact of more than $72 \%$ of the pupils of $7^{\circ}$. Keywords: Theory of the evolution, playful Materials, Teach-learning.

\section{INTRODUÇÃO}

A educação no Brasil possui diversas particularidades, sendo várias delas negativas como a falta de infraestrutura, materiais didáticos defasados, superlotação de salas de aulas, dentre outros. Na educação no campo no município de Marabá/PA encontramos diversos pontos negativos como a falta de transporte, evasão escolar, excesso de alunos em ônibus escolares em péssimo estado, escolas que possuem uma infraestrutura precária, materiais didáticos que possuem uma realidade urbana dificultando a assimilação dos assuntos pelos alunos, os materiais didáticos priorizam valores e culturas distantes da realidade da maioria dos alunos [1].

Com as condições citadas anteriormente, os professores encontram dificuldades em aplicar métodos lúdicos em salas de aulas, devido à falta de disponibilidade de recursos, mas não é impossível, pois a elaboração e adaptação de jogos referente ao cotidiano dos alunos é viável e colaborar na fixação dos assuntos relacionados a diversas disciplinas, levando em consideração o baixo custo de elaboração desses materiais. 
Atividades lúdicas são práticas que visam ao desenvolvimento pessoal do aluno e também são instrumentos que motivam, atraem e estimulam o estudante, e quando possuem regras, essas atividades lúdicas podem ser consideradas jogos [2]. Segundo Oliveira [3] os jogos possibilitam inúmeras maneiras de trabalhar em sala de aula o mesmo conteúdo. Por se tratar de uma atividade geralmente coletiva, incentiva à interação entre os alunos, provocando discussões que podem sanar dúvidas. Dentre as várias atividades propostas, vem se destacando o uso de jogos e atividades lúdicas, descritos frequentemente na literatura [4, 5, 6, 7].

Para Silva [8], os jogos educativos ou didáticos são ações lúdicas destinadas ao desenvolvimento de habilidades cognitivas e a aquisição ou treino de conteúdos específicos. Desta forma os mesmos devem ser elaborados visando à necessidade do grupo onde será aplicado e sua funcionalidade como material lúdico a fim de desenvolver o ensinoaprendizagem. Segundo Silva [9], o lúdico é a forma de desenvolver a criatividade, os conhecimentos e o raciocínio de uma criança por meio de jogos, música e dança. Assim, existem inúmeras maneiras de utilizar o método lúdico na educação e socialização de um indivíduo.

Portanto o material lúdico representado por jogos como de cartas, tabuleiros, bingos entre outros, sendo utilizados através de brincadeiras que para Kishimoto [10] é a ação que a criança desempenha ao concretizar as regras do jogo, ao mergulhar na ação lúdica. Brinca-se por que é prazeroso. Por esse motivo o jogo se torna uma peça de extrema importância quando se quer atrair a atenção do aluno para determinado conteúdo; ao encarar o jogo como uma brincadeira, aprende o conteúdo sem perceber [11].

A partir do exposto anteriormente, podemos perceber que um jogo didático, no que tange aos aspectos gerais, é educativo, pois envolve ações lúdicas, cognitivas, sociais etc., mas nem sempre um jogo que é educativo pode ser considerado um jogo didático. Isso, no entanto, não minimiza nem reduz importância de ambos [12].

O presente trabalho é uma adaptação de um jogo de tabuleiro, levando em consideração a particularidade da educação no campo e as necessidades dos alunos da turma do $7^{\circ}$ ano "A" (turno matutino) promovendo a interação social e colaborando no processo de ensinoaprendizagem.

Este jogo tem como objetivo colaborar na assimilação do conteúdo sobre a teoria da evolução de Lamarck e Darwin, desenvolvendo o ensino-aprendizagem, interação social, desenvolvimento cognitivo através do raciocínio lógico utilizado na execução do jogo de tabuleiro aplicado em sala de aula.

\section{MATERIAL E MÉTODOS}

Os alunos participantes deste projeto foram no total de 18 , que compõem uma turma de $7^{\circ}$ ano "A" de uma escola municipal de ensino fundamental na zona rural do munícipio de MarabáPará. No fim da execução do jogo foi aplicado um questionário contendo 4 perguntas sobre a execução do mesmo.

O tabuleiro (Figura 01) foi confeccionado em papel A4 e colado em cartolina de forma simples e prática, onde foi desenhado um caminho com características da evolução contendo imagens relacionadas ao conteúdo e suas características. 


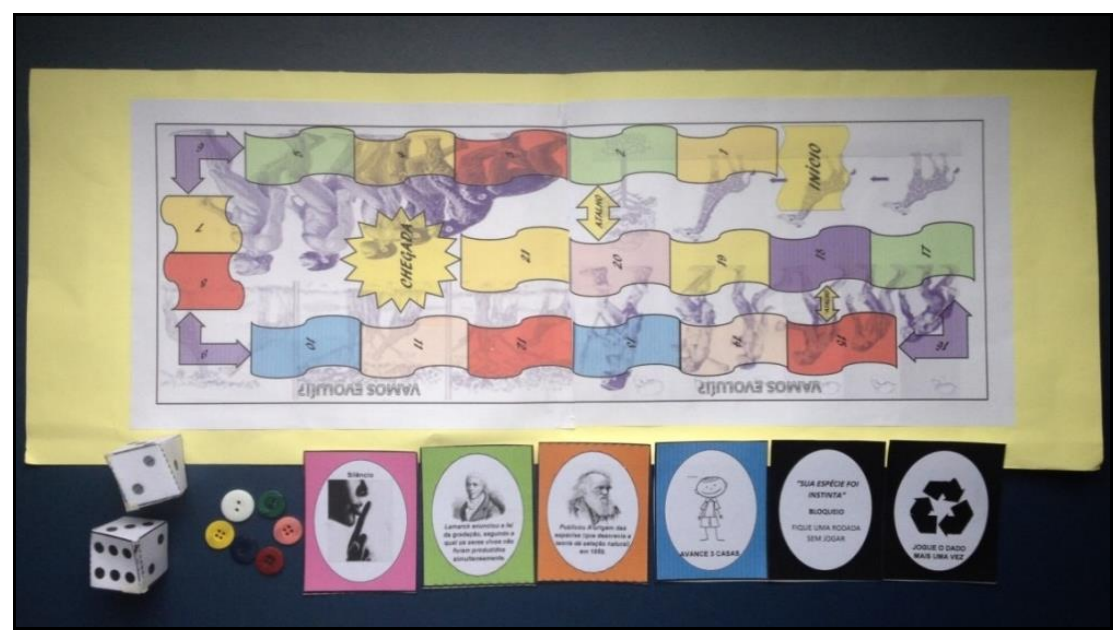

Figura 01: Tabuleiro, dados, botões e cartas que compõem o jogo.

O jogo de tabuleiro é semelhante ao "Jogo Imobiliário" bem conhecido pelos alunos; possui 30 cartas com características dos cientistas Lamarck e Darwin e seus principais feitos, os jogadores foram representados por botões de diversas cores, para execução do jogo utilizou-se dados para direcionamento.

A forma de utilização do tabuleiro, o jogador representado pelo botão, lançará os dados, os números expostos é a quantidade de casas que o mesmo deve andar, em seguida deve-se retirar uma carta. As cartas de ação são no total de 30 contendo características afirmativas sobre as teorias aplicadas e com bônus de posição, por exemplo, o aluno que retirar uma carta sobre a evolução e adaptação de um animal positiva o mesmo poderá caminhar duas casas a modo de ganhar o jogo. No primeiro momento ministrou-se uma aula expositiva sobre teoria da evolução de Lamarck e Darwin (Figura 02), utilizando o livro didático dos alunos para fundamentação do jogo de tabuleiro.

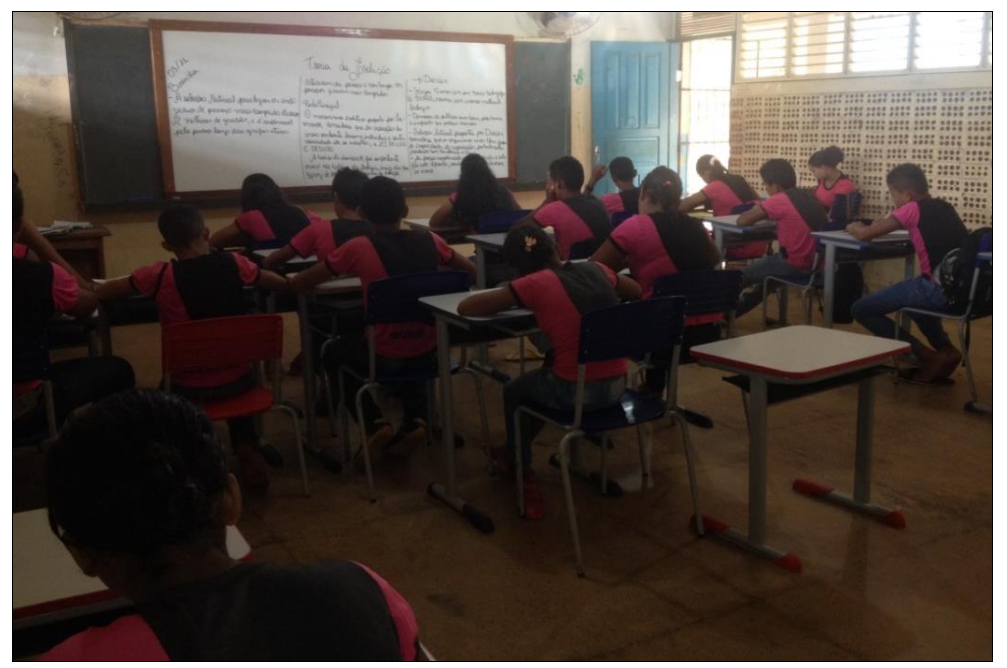

Figura 02: Aula expositiva.

Durante a aplicação do projeto não houve resistência por parte dos alunos aos métodos utilizados, sendo receptivos a utilização do jogo e a aula ministrada, pois $72 \%$ tiveram o primeiro contato ao material lúdico, esperava-se um receio ao utilizarem o jogo proposto.

A turma foi dividida em quatro grupos contendo de 4 a 5 alunos, houve a orientação sobre a utilização do jogo lúdico; em seguida começaram a jogar. Houve dúvidas sobre a teoria da evolução as quais foram sanadas no decorrer da utilização do jogo, assim como houve momentos em que os próprios alunos esclareciam pontos sobre a teoria para seus colegas de classe. 
Um questionário estruturado aplicado com quatro questões fechadas no fim da aula, teve como objetivo buscar a opinião dos alunos sobre a utilização do jogo e o método utilizado. Sendo assim, percebe-se que os alunos estão abertos a novas didáticas de ensino e se interessam pelo assunto, contribuindo de forma positiva com sua participação e senso crítico sobre o assunto.

\section{RESULTADOS E DISCUSSÃO}

As aulas de ciências são vistas pelos alunos como monótonas, com bastante teoria e cansativas. Para retirarmos está impressão sempre que possível podemos programar métodos lúdicos como jogos para auxiliar e fixar os conteúdos trabalhados em sala de aula. Obtendo-se um resultado significativo referente ao desenvolvimento do aluno em sala de aula. Pois a atividade lúdica sempre envolve ações e significados, e estes elementos são em parte a interpretação que a criança faz [8]. Ao propor, por exemplo, uma atividade lúdica para seus alunos, o professor deve efetivamente ter conhecimento dos objetivos a serem alcançados, bem como verificar a adequação metodológica que deseja utilizar à faixa etária com que trabalha, podendo, se isso não ocorrer, o jogo tornar-se uma brincadeira sem objetivos e que os alunos memorizem seus procedimentos sem que haja uma aprendizagem significativa [13].

Durante a aplicação do projeto houve uma grande aceitação dos alunos sobre o método utilizado, estimulando os mesmos a interação social e estímulos lúdicos para a aprendizagem durante a aula.

Referente à primeira questão, Você já possuiu contato com jogos didáticos, com o tema de "A Teoria da Evolução?, $28 \%$ dos alunos tiveram uma resposta afirmativa e $72 \%$ disseram que não. É notável que a maioria dos alunos não possuía acesso a jogos relacionados ao tema, despertando assim a curiosidade em utilizá-lo.

A segunda questão, Como você classifica o Jogo de Tabuleiro, utilizado em sala de aula?, 11\% dos alunos disseram que era regular, $22 \%$ afirmaram que seria bom e $67 \%$ afirmaram que foi ótimo. Os alunos que afirmaram que o método utilizado é bom ou regular propuseram sugestões para melhorar o jogo como tabuleiros com pinos humanos e cartas com mais ações.

Sobre a terceira questão, Com a utilização do jogo de tabuleiro Vamos evoluí, foi possível fixar os assuntos tratados em sala de aula?, 100\% dos alunos disseram que sim. Os alunos após avaliarem o jogo relataram que conseguiram fixar diversas características das teorias proposta em sala de aula, comparando com a aula que tiveram anteriormente com a sua professora de ciências. Sendo que antes e após a aplicação do jogo houve a execução de uma atividade aplicada com questões sobre a teoria da evolução, para verificar a fixação do assunto e compreensão dos alunos, onde evidenciou-se que houve um aproveitamento bastante considerável.

Referente a quarta e última questão, Você gostaria que tivesse mais recursos didáticos como jogos nas aulas de ciências?, todos os alunos relataram que sim. Portanto, foi observado que há grande interesse dos alunos em utilizar métodos lúdicos, onde os mesmos não mostram qualquer tipo de receio, participando de forma prazerosa do jogo de tabuleiro em sala de aula.

Portanto, o intuito é educar e ensinar, enquanto a criança se diverte e interage com os outros, tornando leve é descontraído qualquer aprendizado [6]. Sendo prazeroso aprender por meio lúdico a fim de fixar conteúdos sobre disciplinas e socializando em sala de aula, pois há alunos inibidos a interagir e pelo meio da utilização de jogos é notável a integração no grupo.

Sendo assim, o sentido do jogo é o da ação comunicativa que se desenrola nas brincadeiras [1], percebe-se que os alunos estão abertos a novas didáticas de ensino e se interessam pelo assunto, contribuindo de forma positiva com sua participação e senso crítico. Desta forma o material lúdico utilizado neste trabalho desenvolveu o ensino-aprendizagem, interação social, desenvolvimento cognitivo através do raciocínio lógico, pois no jogo, nunca se tem o conhecimento prévio dos rumos da ação do jogador, que dependerá, sempre, de fatos internos e motivações pessoais, bem como estímulos externos, como a conduta de outros parceiros [1], estimulando os jogadores a montar estratégias para ganhar o jogo. 


\section{CONCLUSÃO}

Os materiais lúdicos são ótimas ferramentas para o auxílio do processo de ensinoaprendizagem, devido a sua forma dinâmica de atuação, onde se pode realizar adaptações conforme as necessidades em sala de aula, utilizando materiais acessíveis e de baixo custo como materiais recicláveis. A aplicação dos jogos em aulas de ciências ou em outras disciplinas possui um papel importante, desde que não fuja do objetivo principal de desenvolvimento do ensino-aprendizagem buscando a fixação do assunto tratado.

Durante a aplicação do jogo os alunos mostraram interesse, participando da aula ministrada com perguntas sobre o assunto e o funcionamento do jogo lúdico, onde em alguns momentos os próprios alunos esclareciam dúvidas de seus colegas de classe durante a utilização do jogo de tabuleiro.

Mediante a resposta do questionário referente à primeira questão onde 13 dos 18 alunos presentes em sala de aula, responderam que seria a primeira vez que tiveram acesso ao jogo lúdico, devido à falta de aplicação de jogos por parte dos professores. Desta forma, os professores devem ser mediadores do ensino e ter a iniciativa de aplicar métodos lúdicos para o ensino.

Sendo assim as respostam foram significativas, onde se observou a boa aceitação do jogo pelos alunos e que o mesmo atingiu o objetivo e propósito real do material lúdico sendo a fixação dos conteúdos de forma a reforçar a aprendizagem, socialização entre os alunos e sanar dúvidas entre eles sobre o tema da teoria da evolução.

\section{AGRADECIMENTOS}

Os autores agradecem a comunidade escolar da E. M. E. F. Professor Raimundo Gomes.

\section{REFERÊNCIAS BIBLIOGRÁFICAS}

1. Pires MGP, Ferreira LG. Livro didático e a realidade rural: apontamento de uma pesquisa. Revista espaço acadêmico, 2011, Fevereiro, $\mathrm{n}^{\circ} 117$.

2. Joyce CSF, Saturnino, Inácio L. e Leandro JS. Pôquer dos Elementos dos Blocos s e p. Química Nova na Escola, 2013;35(3):174-181.

3. Oliveira LMS, Silva OG, Ferreira UVS. Desenvolvendo jogos didáticos para o ensino de química. Ano 26, v. 5, Holos 2010.

4. Oliveira AS. Soares M.H.F.B. Júri químico: uma atividade lúdica para discutir conceitos químicos. Química Nova na Escola, 2005;21:18-24.

5. Santos APB, Michel, RC. Vamos jogar uma SueQuí- mica? Química Nova na Escola, 2009;31(3):179-183.

6. Beneditti FE, Fiorucci, AR, Benedetti, LPS, Craveiro, J.A. Palavras cruzadas como recurso didático no uso de teoria atômica. Química Nova na Escola, 2009;31(2):88-95.

7. Abreu, JG, Cardoso, TMG, Cavalcante, TM, Freitas, DS, Marcelino, LV, Recena, MCP, Mesquita, NAS, Soares, MHFB. Jogos em ensino de química: avaliação da produção científica a partir dos trabalhos publicados nos Encontros Nacionais de Ensino de Química (Período 19962008). IN: Encontro Nacional de Ensino de Química, 15, 2010, 375 p.

8. Silva CCB. O lugar do brinquedo e do jogo nas escolas especiais de educação infantil [Dissertação]. Universidade de São Paulo; 2003.

9. Silva SF. A importância do brincar na educação infantile. Planeta educação; 31/10/2011.

10. Kishimoto TM. Brinquedos e brincadeiras na educação infantile. Anais do I seminario nacional: Curriculo em movimento - Perspectivas atuais; Belo Horizonte; 2010

11. Kishimoto TM. O jogo e a educação infantil e Perspectiva; Florianopolis; UFSC/CED, 1994. $105-128 \mathrm{p}$.

12. Cunha MB. Jogos no Ensino de Química: Considerações Teóricas para sua Utilização em Sala de Aula. Química Nova na Escola, 2012;34(2):92-98.

13. Alexandre S, Paulo Roberto N, A história do lúdico na educação. Revista de Matemática, 2011;6(2):19-36. 